\title{
The Impacts of Smartphone Addiction and Technostress on Customer Satisfaction and Loyalty
}

\author{
DaeEop Kim ${ }^{1}$ and Jae-Ik Shin ${ }^{2 *}$ \\ ${ }^{1}$ Department of Business Administration, Gyeongsang National University, \\ 501 Jinju-Daero, 52828 Jinju, South Korea \\ ${ }^{2}$ Department of E-Business, Gyeongnam National University of Science and \\ Technology, 33 Dongjin-Ro, 52725 Jinju, South Korea \\ sji@gntech.ac.kr
}

\begin{abstract}
As most people use smartphones most of the time, smartphone addiction and technostress are likely to be easily induced. It can be expected that excessive smartphone addiction and technostress will have negative effects on customer satisfaction and loyalty. This study explores the effects of flow and social interaction anxiety on smartphone addiction, and investigates the relationships between addiction, technostress, customer satisfaction and loyalty. A total of 342 valid questionnaires were collected from university students who live in Gyeongnam province in South Korea. Eight hypotheses were examined using SmartPLS software. The findings indicated that flow and social interaction anxiety have positive impacts on smartphone addiction. Smartphone addiction has positive impacts on technostress and customer loyalty but does not affect customer satisfaction. Technostress has a negative effect on customer satisfaction but does not affect customer loyalty. Customer satisfaction is strongly associated with customer loyalty. The implications of these results are discussed and directions for future research are offered.
\end{abstract}

Keywords: Flow, Social interaction anxiety, Smartphone addiction, Technostress, Customer satisfaction, Customer loyalty

\section{Introduction}

It is expected that smartphone users will exceed 6.1 billion people by 2020 due to the rapid advance of mobile Internet infrastructure and smart devices [1]. Smartphone based services have increased the efficiency of online shopping, communication, learning, and making payments [2]. Thus, smartphones have already become a daily necessity.

The issues of smartphone addiction and technostress are brought up because many people tend to use smartphones excessively. Interestingly, Lu and Wang [3] suggested that people who are addicted to online games remain loyal even if they are unsatisfied. This implies that the appropriate level of smartphone addiction may help to retain customer loyalty. Few previous studies have investigated the positive role of smartphone addiction to enhance customer loyalty [4].

Many researchers have examined the antecedents and effects of technostress [5]. Technostress is likely to decrease continuous usage intention for various technologies [6]. Technostress related to smartphone use can lower the level of customer satisfaction and loyalty. Thus, the objective of this study is to identify the antecedents and consequences of smartphone addiction and technostress, and to provide the implications beyond the dark side of smartphone usage.

* Corresponding Author 


\section{Literature Review}

Consumers of smartphones can get benefits such as social networking, shopping, gaming, and work or information apps. They have depended greatly on smartphones to search useful information by a simple browse and click when they commute, relax at home, and travel overseas [7]. In order to understand user behavior and to sustain sales of smartphones and its market share, researchers and managers should focus on the cause and effect behind smartphone dependency or addiction [8].

Flow is defined as an experience that an individual has by concentrating on what $\mathrm{s} / \mathrm{he}$ does and being curious about the action. It is believed to be fun by the person [9]. Some researchers suggested that flow has significant impacts on attitude towards websites such as perception, satisfaction, and evaluation [10,11, and 12]. Previous studies have shown that flow has hedonic and utilitarian characteristics. Recently, researches have been likely to adopt flow theory to describe online consumer behavior in different settings and platforms [13].

Social interaction anxiety can be defined as an excessive fear of social interactions with others and of being evaluated by other people when encountering strangers in public situations [14]. Previous studies have revealed that anxious individuals positively derive benefit from online social interaction [15]. However, this group of people tend to become Internet addicts [16]. Because 83\% of smartphone users employ their phone for communication [17], it is expected that people with high social interaction anxiety will be more inclined to become smartphone addicts than those with low social interaction anxiety.

Many users consider smartphones as a part of themselves and get emotionally attached to their smartphones. They also feel uneasy and nervous when not having the phone close by and cannot use it [18]. This situation can easily make the users smartphone addicted [19]. Meanwhile, Oulasvirta et al. [20] consider repetitive checking of smartphones as a compulsive behavior. This implies that the compulsive usage of smartphones can be seen as smartphone addiction. Lee et al. [21] argued that compulsive usage of smartphones positively affects technostress. Kim and Shin [4] suggested that smartphone addiction positively influences customer loyalty but does not influence customer satisfaction.

Brod [22] defined technostress as a modern disease of adaptation caused by new computer technologies. The seriousness of technostress stems from the rapid growth of mobile services and technologies [21]. Technostress may discourage from using continuously various technologies [6]. In this research, technostress refers to stress related to the use of smartphones.

Customer satisfaction is defined as the overall feelings, or attitude that an individual consumer has about a product or service [23]. The personal and self-fulfilling benefit that users obtain from interacting with a technology can influence satisfaction. Fun and enjoyment of using a technology also play a role in enhancing the level of customer satisfaction [24]. User satisfaction is affected by cognitive and affective perceptions of smartphones [25].

Customer loyalty refers to a commitment to repurchase, recommend, and spread a preferred product or service by word of mouth in the future [26]. Every firm focuses on building loyal customers. Previous studies showed that customer satisfaction is the significant way to get customer loyalty [27]. Because overdependence or addiction to smartphones may lead to compulsive usage and enhance user technostress [21], it is expected that an examination of the relationship between technostress and customer loyalty will provide a significant implication. Therefore, the following hypotheses are proposed to identify how smartphone addiction and technostress affect customer satisfaction and loyalty. 
H1 Flow will have a positive effect on smartphone addiction.

$\mathrm{H} 2$ Social interaction anxiety will have a positive effect on smartphone addiction.

H3 Smartphone addiction will have a positive effect on customer satisfaction.

H4 Smartphone addiction will have a positive effect on customer loyalty.

H5 Smartphone addiction will have a positive effect on technostress.

H6 Customer satisfaction will have a positive effect on customer loyalty.

H7 Technostress will have a negative effect on customer satisfaction.

H8 Technostress will have a negative effect on customer loyalty.

\section{The Research}

This study is designed to examine the effects of smartphone addiction and technostress on customer satisfaction and loyalty and the impacts of flow and social interaction anxiety on the addiction. The research model is shown in Figure 1.

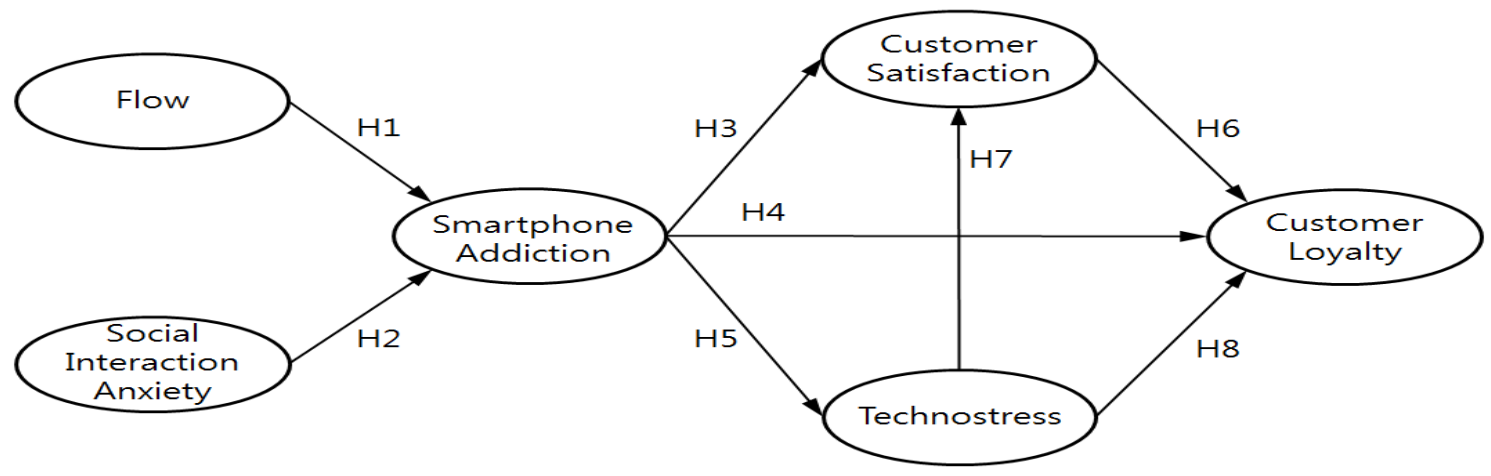

Figure 1. Proposed Model

For this, a survey was conducted in the Gyeongnam province from May 30 to Jun 10, 2016 and of the 370 questionnaires, 28 questionnaires were eliminated because of missing data, resulting in a final sample of 342 university students. The participants were asked to respond to the survey questionnaires based on their most recent experience of smartphone addiction and technostress. SPSS 18.0 and PLS (Partial Least Squares) 2.0 of statistical package were used to analyze the data and test the hypotheses. This study chose PLS method to test the hypotheses because its advantage is suitable for predictive application [28].

A self-reported questionnaire was developed for this study. The survey included the perceptions of flow, social interaction anxiety, smartphone addiction, customer satisfaction, technostress, customer loyalty, and demographic information. The study has six variables, with each variable having multiple items that are measured by a five-point Likert scale $(1=$ strongly disagree and $5=$ strongly agree). The items used to operationalize the constructs were mainly adapted from previous studies and modified in the context of the research.

Three items of flow indicated the degree of immersion when using smartphones [29]. Eight items of social interaction anxiety indicated the degree of anxiety when interacting with other people [21]. Fourteen items of smartphone addiction indicated the degree of disturbance of adaptive function, virtual life orientation, withdrawal, and tolerance [30]. Five items of technostress indicated the degree of stress related to smartphone use [21]. Three items of customer satisfaction indicated the degree of satisfaction related to smartphone use and choice [12]. Three items of customer loyalty indicated the degree of loyalty related to smartphone use and recommendation [12]. 


\section{Findings}

Among 342 respondents, 50.9 percent were male and 49.1 percent were female. 61.6 percent were between 18 to 21 years old and 29.2 percent were between 22 to 24 years old. 9.2 percent were above 25 years old. In the mobile service providers of South Korea, 42.4 percent were SKT, 35.7 percent were KT, and 20.2 percent were LG U Plus.

Table 2. Measurement Model

\begin{tabular}{|c|c|c|c|}
\hline Age & $\%$ & Mobile service provider & $\%$ \\
\hline $18-21$ & 61.6 & SKT & 42.4 \\
\hline $22-24$ & 29.2 & KT & 35.7 \\
\hline $25 \geq$ & 9.2 & LG U+ & 20.2 \\
\hline Expense of the service & & missing & 1.8 \\
\hline$\leq \forall 39,999$ & 37.1 & Gender & Frequency \\
\hline$\forall 40,000 \sim \forall 69,999$ & 40.6 & female & 174 \\
\hline$\geq \# 70,000$ & 21.9 & male & 168 \\
\hline missing & 0.3 & & \\
\hline
\end{tabular}

In PLS, the composite reliability is advisable to identify internal consistency and the acceptable value should exceed 0.70 [31]. The results as shown in Table 2 indicated that all constructs have a value more than 0.70 and thus internal consistency is identified. Construct validity can be tested by discriminant and convergent validity [32]. The findings showed that AVE in all constructs is more than 0.5 and thus convergent validity is achieved. Fornell and Larcker [33] proposed that a correlation between two constructs should be lower than the squared root of the AVE value for any of the two constructs. Table 3 showed that all constructs have discriminant validity.

Table 2. Measurement Model

\begin{tabular}{|c|c|c|c|c|c|}
\hline Paths of outer model & coeff. $^{a}$ & S.E. ${ }^{b}$ & t-value & $\begin{array}{l}\text { Composite } \\
\text { Reliability }\end{array}$ & AVE \\
\hline flow $1 \leftarrow$ FLOW & 0.828 & 0.039 & 21.109 & \multirow{3}{*}{0.887} & \multirow{3}{*}{0.723} \\
\hline flow $2 \leftarrow$ FLOW & 0.905 & 0.023 & 38.623 & & \\
\hline flow3 $\leftarrow$ FLOW & 0.816 & 0.041 & 19.981 & & \\
\hline sia $1 \leftarrow$ SIA & 0.634 & 0.046 & 13.937 & \multirow{7}{*}{0.896} & \multirow{7}{*}{0.521} \\
\hline $\operatorname{sia} 2 \leftarrow$ SIA & 0.828 & 0.019 & 44.388 & & \\
\hline $\operatorname{sia} 3 \leftarrow$ SIA & 0.788 & 0.028 & 27.717 & & \\
\hline sia $4 \leftarrow$ SIA & 0.665 & 0.046 & 14.620 & & \\
\hline sia $5 \leftarrow$ SIA & 0.742 & 0.035 & 20.976 & & \\
\hline sia6 $\leftarrow$ SIA & 0.628 & 0.050 & 12.498 & & \\
\hline sia $7 \leftarrow$ SIA & 0.764 & 0.026 & 29.196 & & \\
\hline
\end{tabular}




\begin{tabular}{|c|c|c|c|c|c|}
\hline $\operatorname{sia} 8 \leftarrow$ SIA & 0.701 & 0.038 & 18.275 & & \\
\hline mdaf $^{c} \leftarrow$ ADDICTION & 0.803 & 0.027 & 29.705 & \multirow{4}{*}{0.840} & \multirow{4}{*}{0.570} \\
\hline mtol $^{\mathrm{c}} \leftarrow$ ADDICTION & 0.788 & 0.034 & 23.180 & & \\
\hline mvlo $^{c} \leftarrow$ ADDICTION & 0.618 & 0.056 & 11.048 & & \\
\hline $\operatorname{mwdr}^{\mathrm{c}} \leftarrow$ ADDICTION & 0.795 & 0.023 & 34.390 & & \\
\hline cs $1 \leftarrow$ SATISFACTION & 0.895 & 0.015 & 58.165 & \multirow{3}{*}{0.911} & \multirow{3}{*}{0.774} \\
\hline $\operatorname{cs} 2 \leftarrow$ SATISFACTION & 0.875 & 0.020 & 44.263 & & \\
\hline cs $3 \leftarrow$ SATISFACTION & 0.869 & 0.018 & 47.222 & & \\
\hline loy $1 \leftarrow$ LOYALTY & 0.795 & 0.023 & 34.075 & \multirow{3}{*}{0.843} & \multirow{3}{*}{0.642} \\
\hline loy $2 \leftarrow$ LOYALTY & 0.851 & 0.018 & 46.860 & & \\
\hline loy $3 \leftarrow$ LOYALTY & 0.755 & 0.037 & 20.521 & & \\
\hline tchs $1 \leftarrow$ TCHNOSTRESS & 0.804 & 0.022 & 36.659 & \multirow{5}{*}{0.860} & \multirow{5}{*}{0.553} \\
\hline tchs $2 \leftarrow$ TCHNOSTRESS & 0.792 & 0.033 & 24.242 & & \\
\hline tchs $3 \leftarrow$ TCHNOSTRESS & 0.773 & 0.032 & 24.169 & & \\
\hline tchs $4 \leftarrow$ TCHNOSTRESS & 0.611 & 0.057 & 10.656 & & \\
\hline tchs $5 \leftarrow$ TCHNOSTRESS & 0.720 & 0.044 & 16.541 & & \\
\hline \multicolumn{6}{|c|}{$\begin{array}{l}\text { a. All of coefficients are significant at } 0.01 \text { level } \\
\text { b. Bootstrap option: No sign change and } 5000 \text { samples } \\
\text { c. Sub-constructs of smartphone addiction were transformed into summated scales. } \\
\text { d. SIA: Social Interaction Anxiety }\end{array}$} \\
\hline
\end{tabular}

Table 3. Correlation Matrix

\begin{tabular}{|l|c|c|c|c|c|c|}
\hline & FLOW & SIA & ADDICT & SAT & LOY & TCHS \\
\hline FLOW & $\mathbf{0 . 8 5 1}$ & & & & & \\
\hline SIA & 0.098 & $\mathbf{0 . 7 2 2}$ & & & & \\
\hline ADDICT & 0.281 & 0.368 & $\mathbf{0 . 7 5 5}$ & & & \\
\hline SAT & 0.218 & 0.029 & -0.013 & $\mathbf{0 . 8 8 0}$ & & $\mathbf{0 . 8 0 1}$ \\
\hline LOY & 0.222 & 0.011 & 0.082 & 0.690 & -0.128 & $\mathbf{0 . 7 4 3}$ \\
\hline TCHS & -0.060 & 0.222 & 0.429 & -0.184 & \\
\hline $\begin{array}{l}\text { Elements on diagonal are square roots of AVEs. } \\
\text { SIA: Social Interaction Anxiety, ADDICT: Addiction, SAT: Satisfaction, LOY: Loyalty, }\end{array}$ \\
TECH: Techostress
\end{tabular}

The estimation results from SmartPLS software are shown in Figure 2, and six paths among constructs are positive and significant at the 0.01 and 0.05 levels. The model validity was evaluated by $R$ square value and the structural paths [34]. The $R$ square for smartphone addiction meant that $20 \%$ of the variance in this construct is accounted by flow and social interaction anxiety. The R square for technostress meant that $18 \%$ of the 
variance in this construct is accounted for by smartphone addiction. The $\mathrm{R}$ square for customer satisfaction meant that $4 \%$ of the variance in this construct is accounted for by smartphone addiction and technostress. The R square for customer loyalty meant that $49 \%$ of the variance in this construct is accounted for by smartphone addiction, technostress, and customer satisfaction. The catch here is the possibility that the effects of smartphone addiction and technostress on customer satisfaction could be negative or none. Hence, the result of R square indicates an overall satisfactory level of explanation.

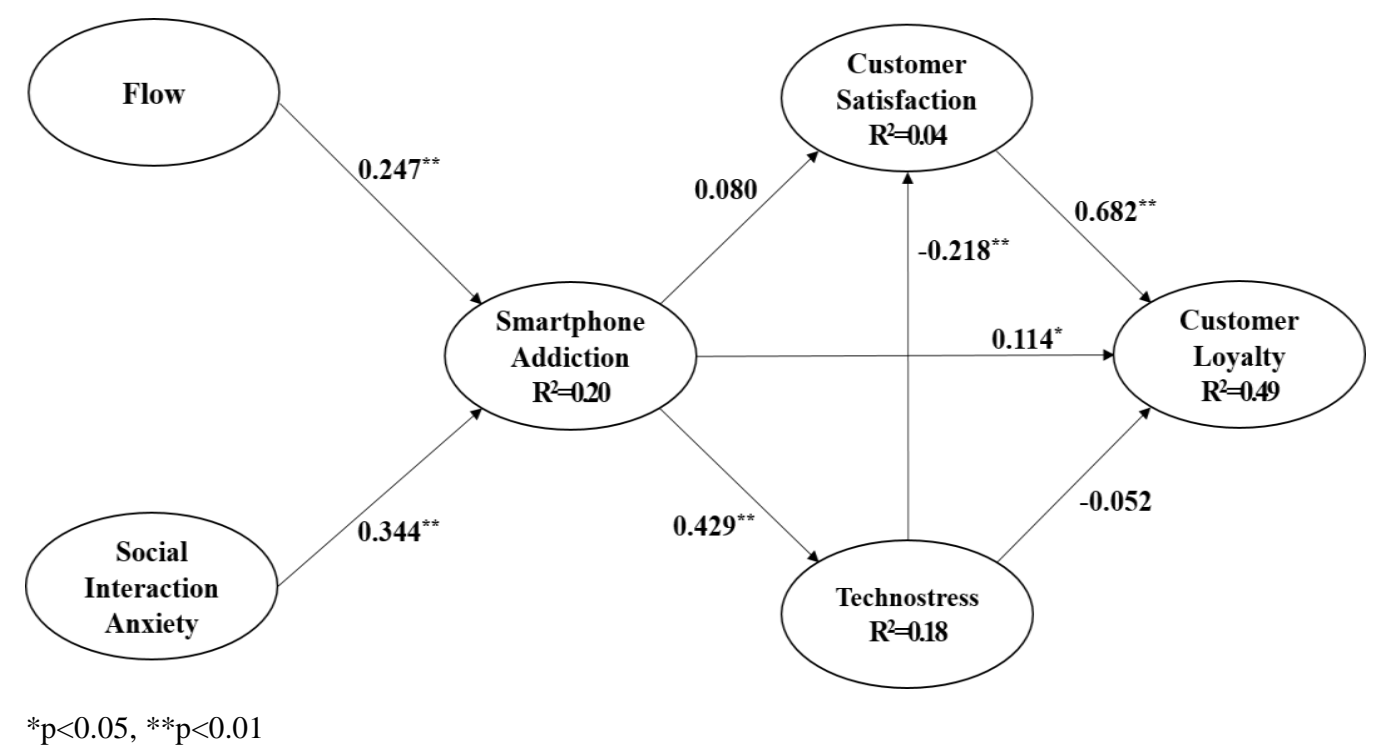

Figure 2. Results of PLS Analysis Model

According to the path coefficients, the effect of social interaction anxiety on smartphone addiction (0.344) is stronger than that of flow (0.247). This indicates that social interaction anxiety has more impact on smartphone addiction than flow. The effect of smartphone addiction on technostress (0.429) is significant and that of the addiction on customer satisfaction $(0.080)$ is not significant. This means that smartphone addiction is a good predictor for technostress but is not a predictor for customer satisfaction. The effect of technostress on customer satisfaction $(-0.218)$ is significant. This implies that technostress is a negative predictor for customer satisfaction. The effect of customer satisfaction on customer loyalty (0.682) is stronger than that of smartphone addiction (0.114). This means that customer satisfaction has more influence on customer loyalty than smartphone addiction does. However, the effect of technostress on customer loyalty $(-0.052)$ is not significant. This indicates that technostress is not a predictor for customer loyalty. Therefore, the results of path coefficient analysis reveal that customer satisfaction is the most important factor in determining customer loyalty, followed by smartphone addiction.

Table 4. Results of Path Analysis

\begin{tabular}{|l|c|c|c|l|}
\hline \multicolumn{1}{|c|}{ Path } & coeff. & S.E. $^{\mathrm{a}}$ & $\mathrm{t}$ & \multicolumn{1}{|c|}{ Hypotheses } \\
\hline FLOW $\rightarrow$ ADDICT & $0.247^{* *}$ & 0.051 & 4.890 & H1 accepted \\
\hline SIA $\rightarrow$ ADDICT & $0.344^{* *}$ & 0.054 & 6.397 & H2 accepted \\
\hline ADDICT $\rightarrow$ SAT & 0.080 & 0.063 & 1.277 & H3 rejected \\
\hline
\end{tabular}




\begin{tabular}{|l|c|c|c|l|}
\hline ADDICT $\rightarrow$ LOY & $0.114^{*}$ & 0.044 & 2.554 & H4 accepted \\
\hline ADDICT $\rightarrow$ TCHS & $0.429^{* *}$ & 0.053 & 8.167 & H5 accepted \\
\hline SAT LOY & $0.682^{* *}$ & 0.034 & 19.868 & H6 accepted \\
\hline TCHS SAT & $-0.218^{* *}$ & 0.062 & -3.496 & H7 accepted \\
\hline TCHS $\rightarrow$ LOY & -0.052 & 0.050 & -1.034 & H8 rejected \\
\hline $\begin{array}{l}\text { a. Bootstrap option: No sign change and 5000 samples } \\
* \mathrm{p}<0.05, * * \mathrm{p}<0.01\end{array}$ \\
$\begin{array}{l}\text { SIA: Social Interaction Anxiety, ADDICT: Addiction, SAT: Satisfaction, LOY: Loyalty, } \\
\text { TECH: Technostress }\end{array}$
\end{tabular}

\section{Conclusions}

A research model of smartphone addiction has been developed from the positive and negative aspects. The findings of this study reveal that consumers are increasingly getting smartphone addicted due to flow and social interaction anxiety. Interestingly, smartphone addiction is a positive predictor for technostress and customer loyalty. Meanwhile, technostress negatively affects customer satisfaction, however, smartphone addiction does not affect customer satisfaction. Thus, appropriate smartphone addiction and technostress can help to enhance customer satisfaction and loyalty.

This study highlights the roles of smartphone addiction and technostress constructs and how they affect customer satisfaction and loyalty. The practical contribution of this research emphasizes the importance of keeping the optimal level of smartphone use to prevent excessive smartphone addiction and technostress. Because smartphones are everywhere around us and "virtual realities" are one step ahead, the need to be always connected may easily transform into smartphone addiction [19]. Thus, it is important for firms to educate consumers on the harm of excessive smartphone addiction and technostress and to make efforts to turn the optimal levels of smartphone addiction and technostress into customer satisfaction and loyalty. This implies that profit streams can come from psychological factors of smartphone users such as addiction and technostress. It is important to remember that the companies should focus on the bright side of smartphone addiction and technostress of the users in order to enhance customer loyalty

In terms of theoretical implications, this study proposes a new model of smartphone addiction and technostress to predict customer satisfaction and loyalty. This research develops the literature of smartphone addiction by introducing flow, social interaction anxiety, and technostress through an empirical study. Meanwhile, previous research has shown that satisfaction may not be the best predictor of customer loyalty [35]. Thus, it is expected that smartphone addiction and technostress will be frequently used to assess the performance of customer loyalty in the future study.

The study is not without limitations. As we utilized a limited number of predictors, future research is needed to take into consideration other possible factors, which may be significantly associated with social and psychological factors. Another limitation is that we utilized a cross-sectional sample with questionnaires. Longitudinal data may be more appropriate for this type of research in that the linkage among social factors, psychological factors, and behavioral intentions is established over time. 


\section{References}

[1] Ericsson Mobility Report, "90 Percent to Have Mobile Phones by 2020”, (2014), pp. 2-7.

[2] K.-L. Hsiao, Y. Shu and T.-C. Huang, "Exploring the Effect of Compulsive Social App Usage on Technostress and Academic Performance: Perspectives from Personality Traits", Telematics and Informatics, vol. 34, (2017), pp. 679-690.

[3] H. P. Lu and S. Wang, "The Role of Internet Addiction in Online Game Loyalty: An Exploratory Study", Internet Research, vol. 18, no. 5, (2008), pp. 499-519.

[4] D. Kim and J.-I. Shin, "The Relationship between Social Factor, Dependency, Addiction, and Behavioral Intentions of Smartphone", International Journal of $\mathrm{u}$ - and e-Service, Science and Technology, vol. 9, no. 10, (2016), pp. 255-264.

[5] C. Maier, S. Laumer, C. Weinert and T. Weitzel, "The Effects of Technostress and Switching Stress on Discontinued Use of Social Networking Services: A Study of Facebook Use", Information Systems Journal, vol. 25, no. 3, (2015), pp. 275-308

[6] M. Tarafdar, Q. Tu and T. S. Ragu-Nathan, "The Impact of Technostress on End-User Satisfaction and Performance", Journal of Management Information Systems, vol. 27, iss. 3, (2010), pp. 303-334.

[7] G. L. Genova, "The Anywhere Office = Anywhere Liability", Business Communication Quarterly, vol. 73, (2010), pp. 119-126.

[8] A. Harun, L. T. Soon, A. W. M. Kassim and R. S. Sulong, "Smartphone Dependency and Its Impact on Purchase Behavior", Asian Social Science, vol. 11, no. 26, (2015), pp. 196-211.

[9] H. Chen, R. T. Wigand and M. Nilan, "Exploring Web Users' Optimal Flow Experience", Information Technology \& People, vol. 13, no. 4, (2000), pp. 263-281.

[10] R. Agarwal and E. Karahanna, "Time Flies When You're Having Fun: Cognitive Absorption and Beliefs about Information Technology Usage", MIS Quarterly, vol. 24, no. 4, (2000), pp. 665-694.

[11] M. J. Sanchez-Franco, "Exploring the Influence of Gender on the Web Usage via Partial Least Squares", Behaviour \& Information Technology, vol. 25, no. 1, (2006), pp. 19-36.

[12] L. Deng, D. E. Turner, R. Gehling and B. Prince, "User Experience, Satisfaction, and Continual Usage Intention of IT", European Journal of Information Systems, vol. 19, no. 1, (2010), pp. 60-75.

[13] B. Y. Ozkara, M. Ozmen and J. W. Kim, "Exploring the Relationship between Information Satisfaction and Flow in the Context of Consumers' Online Search", Computers in Human Behavior, vol. 63, (2016), pp. 844-859.

[14] B. R. Schlenker and M. R. Leary, "Social Anxiety and Self-Presentation: A Conceptualization and Model", Psychological Bulletin, vol. 92, no. 3, (1982), pp. 641-669.

[15] J. Y. Yen, C. F. Yen, C. S. Chen, P. W. Wang, Y. H. Chang and C. H. Ko, "Social Anxiety in Online and Real-Life Interaction and Their Associated Factors", CyberPsychology, Behavior \& Social Networking, vol. 15, no. 1, (2012), pp. 7-12.

[16] S. E. Caplan, "Problematic Internet Use and Psychosocial Well-Being: Development of a Theory-Based Cognitive-Behavioral Measurement Instrument”, Computers in Human Behavior, vol. 18, no. 5, (2002), pp. 553-575.

[17] Our Mobile Planet, Google, Retrieved from http://www.thinkwithgoogle.com/mobileplanet/ en/graph/?wave=2012\&age=all\&gender=all\&chart_type=\&active=wave. $\mathbf{( 2 0 1 3 )}$.

[18] S. P. Walsh, K. M. White, S. Cox and M. Y. Ross, "Keeping in Constant Touch: The Predictors of Young Australians' Mobile Phone Involvement", Computers in Human Behavior, vol. 27, no. 1, (2011), pp. 333-342.

[19] M. Roman, A. Saniuta and N. A. Pop, "When does Loyalty Transform into Addiction? Desk research in Telecommunication Services", International Journal of Education and Research, vol. 1, no. 4, (2013), pp. $1-10$

[20] A. Oulasvirta, T. Rattenbury, L. Ma and E. Raita, "Habits Make Smartphone Use More Pervasive", Personal and Ubiquitous Computing, vol. 16, no. 1, (2012), pp. 105-114.

[21] Y.-K. Lee, C.-T. Chang, Y. Lin and Z.-H. Cheng, "The Dark Side of Smartphone Usage: Psychological Traits, Compulsive Behavior and Technostress", Computers in Human Behavior, vol. 31, (2014), pp. 373-383.

[22] C. Brod, "Technostress: The Human Cost of the Computer Revolution", Addison Wesley Publishing Company, MA, (1984)

[23] M. R. Solomon, G. W. Marshall and E. W. Stuart, "Marketing: Real People, Real Choices (8ed.)", Pearson, New York, (2015).

[24] H. Van der Heijden, "User Acceptance of Hedonic Information Systems", MIS Quarterly, vol. 28, no. 4, (2004), pp. 695-704.

[25] D. U. Kim, J. S. Oh and J. I. Shin, "The Effect of Social Factor on Smartphone Dependency and Purchasing Process", The Journal of Internet Electronic Commerce Research, vol. 16, no. 1, (2016), pp. 79-94.

[26] P. Kotler and K. L. Keller, "Marketing Management (14ed.)", Pearson, New York, (2012).

[27] R. L. Oliver, “Whence Consumer Loyalty?", Journal of Marketing, vol. 63, no. 4, (1999), pp. 33-44.

[28] J. C. Anderson and D. W. Gerbing, "Structural Equation Modeling in Practice: A Review and Recommended Two-Step Approach", Psychological Bulletin, vol. 103, no. 3, (1988), pp. 411-423. 
[29] D.-H. Bae, "User Acceptance of Smartphone: Integrated Trust, Self-Efficacy, and Flow with TAM", The e-Business Studies, vol. 14, no. 12, (2013), pp. 47-68.

[30] D. Kim, Y. Lee, J. Lee, J. K. Nam and Y. Chung, "Development of Korean Smartphone Addiction Proneness Scale for Youth", Plos One, vol. 9, no. 5, (2014), pp. 1-8.

[31] M. McLure and S. Faraj, "Why Should I Share? Examining Social Capital and Knowledge Contribution in Electronic Networks of practice", MIS Quarterly, vol. 29, no. 1, (2005), pp. 35-57.

[32] W. W. Chin, A. Gopal and W. D. Salisbury, "Advancing the Theory of Adaptive Structuration: The Development of a Scale to Measure Faithfulness of Appropriation", Information Systems Research, vol. 8, no. 4, (1997), pp. 342-367.

[33] C. Fornell and D. Larcker, "Evaluating Structural Equation Models with Unobservable Variables and Measurement Error", Journal of Marketing Research, vol. 18, no. 1, (1981), pp. 39-50.

[34] P. Chwelos, I. Benbasat and A. S. Dexter, "Research Report: Empirical Test of an EDI Adoption Model”, Information Systems Research, vol. 12, no. 3, (2001), pp. 304-321.

[35] D. Mutum, E. M. Ghazali, B. Nguyen and D. Arnott, "Online Loyalty and Its Interaction with Switching Barriers", Journal of Retailing and Consumer Services, vol. 21, iss. 6, (2014), pp. 942-949.

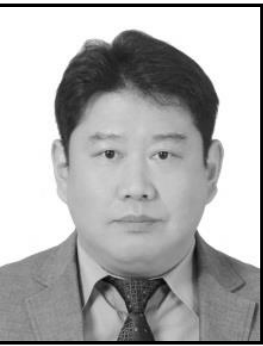

DaeEop Kim is a lecturer in the College of Business at Gyeonsang National University, South Korea. He received his Ph.D in Management from Gyeonsang National University. His favorite research issues are consumers' and organizational behaviors, and methodology. He has published papers in journals such as Journal of Enterprising Culture, The Journal of Internet Electronic Commerce Research, Journal of Korea Service Management Society, Korean Journal of Business Research, etc. He also wrote a book on utilizing structural equation modeling.

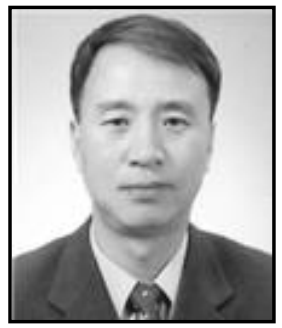

Jae-Ik Shin is an Assistant Professor of the Department of EBusiness at Gyeongnam National University of Science and Technology, South Korea. He received his Ph.D. in Management from Gyeongsang National University, South Korea. His current research interests include Internet marketing, tourism marketing, corporate social responsibility, and service marketing. He has published papers in journals such as International Journal of Information Management, INFORMATION (Japan), ICIC Express Letters, Part B: Applications, Asia Pacific Journal of Marketing and Logistics, International Journal of u- and e- Service, Science and Technology, International Journal of Software Engineering and Its Applications, International Journal of Security and Its Applications, Korean Journal of Tourism Research, The Journal of Internet Electronic Commerce Research, The Academy of Customer Satisfaction Management, International Journal of Business and Information, and Journal of the Korea Entrepreneurship. 
International Journal of Security and Its Applications

Vol. 10, No. 12 (2016) 